\title{
Scientific Incentive Mechanism of College English Teachers
}

\author{
Xiaofang Zhang \\ College of International Studies, Southwest University \\ Pass College, Chongqing Technology and Business \\ University \\ Chongqing, China \\ Email: swuzxf1984@163.com
}

\author{
Jianhui Liu \\ College of Economics \& Management \\ Southwest University \\ Chongqing, China \\ Email:1jh06@swu.edu.cn
}

\begin{abstract}
Base on the principal-agent theories, this paper, from the angle of institutional economics, compares the optimal incentive contract on college English teachers under single-period moral hazard and under repeated moral hazard and introduces tenure contract in the model of repeated moral hazard. Our study finds the following results: (1) in the pretenure period under tenure contract with repeated moral hazard, the principal pays less to college English teachers to promote their incentive of hard-working in scientific research than in the case of single-period moral hazard; (2) college English teachers with tenure are much more difficult to be stimulated to work hard in scientific research and the college management layer has to pay much more to them for their hard work in academic field; (3) tenure system is cost-efficient in the pre-tenure period but is not necessarily cost-efficient in the tenure period.
\end{abstract}

Keywords-institutional economics; incentive mechanism; scientific research; college English teachers; tenure system.

\section{INTRODUCTION}

College English teachers are responsible for the teaching of general English skills in colleges and universities and they are frequently found to pay much attention and importance to English teaching but neglect the academic research in English language. There are many actual reasons: first, in most colleges and universities, college English teachers are pitched as teachers for common required course and academic research is not their ground work; second, it is much more difficult for college English teachers to publish their papers or reports on journals, newspapers, etc. as there are less journals in the field of English language than in other discipline fields; third, there is a lack of incentive scheme to stimulate college English teacher to work hard in scientific research.

However, it is difficult to design a proper incentive scheme for college English teachers to work hard in scientific research as there is always asymmetric information between the college management layer and the English teachers. To solve this problem, this paper will investigate into the incentive scheme for college English teachers to promote their effort in scientific research.

\section{THE MODEL}

There is typical principal-agent problem between the teachers and the management layer of colleges and universities, which originates from the asymmetric information between the teachers and the college management layer. The asymmetric information between the two can be categorized into two types: one the one hand, teachers know well their own type (hardworking or effortless) while the management layer does not possess enough information about their types; one the other hand, the effort devoted by the teachers to scientific research cannot be easily measured and the management layer have to substitute the output of scientific work for the teachers' effort as the effort cannot be observed easily.

\section{A. Hypotheses of the Model}

In our model, suppose that the teachers are homogeneous, namely the asymmetric information about the teachers' effort types is neglected and only the asymmetric information of teachers' effort is taken into consideration. Suppose there are two possible effort levels of the teachers, denoted by $e \in(0,1)$ and that the increasing effort decreases the teachers' utility $\varphi(e)$, where $\varphi(0)=0, \varphi(1)=\varphi$. The scientific effort of teachers confronts uncertainty of output, denoted by $Y$, which includes two possibilities $Y \in(H, L)$, where $H, L$ respectively represents high scientific output and low scientific output. Besides, the scientific output is affected by scientific effort in terms of probability. It is proper to suppose $\operatorname{Pr}(Y=H \mid e=0)=0, \operatorname{Pr}(Y=H \mid e=1)=\pi, \pi>0$.

Obviously, the increase of scientific effort $e$ increases scientific output in terms of first-order stochastic dominance. The management layer pay college teachers salary $W_{h}$ and $W_{l}$ respectively according to their scientific output $H$ and $L$. In our model, the teachers are supposed to be strict risk avoiders and their utility function is in "V-N-M" form, namely $U=u(W)-\varphi(e)$, where $u^{\prime}>0$ and $u^{\prime \prime}<0$. Define $w(u)=u^{-1}(W)$ and accordingly $w^{\prime}>0$ and $w^{\prime \prime}<0$. However, the principal (the management layer) is riskneutral and its utility function is $V=Y-W$. In addition, the reserved utility of college teachers is set at zero. 


\section{B. Optimal Incentive Contract under Single-Period Moral Hazard}

College English teachers generally attach much more importance to English teaching than to English academic research. Besides, the scientific research in English is much more difficult to be published in academic journals and it seems that college English teachers are not provided enough incentive to devote themselves in scientific research. In view of this situation, moral hazard problem is unavoidable under asymmetric information as the effort of college English teachers cannot be easily observed and accurately measured. College English teachers are apt to taking opportunistic actions and being indolent on scientific research. Therefore, the management layer should design an incentive mechanism to promote teachers to pay more attention to scientific research. The programming problem of the management layer is:

$$
\begin{aligned}
& (P): \max _{W_{h}, W_{l}} \pi\left(h-W_{h}\right)+(1-\pi)\left(L-W_{l}\right) \\
& \text { s.t. }(I R) \pi u\left(W_{h}\right)+(1-\pi)\left(W_{l}\right)-\varphi=0 \\
& (I C) \pi\left(u\left(W_{h}\right)-\varphi\right)+(1-\pi)\left(u\left(W_{l}\right)-\varphi\right) \geq u\left(W_{l}\right)
\end{aligned}
$$

Where $I R$ and $I C$ respectively represents the participation constraint and incentive compatible constraint of the agent (college English teachers).

To guarantee the problem a concave programming, we change the null programming $(\mathrm{P})$ through variable substitution. Let $u_{h}=u\left(W_{h}\right)$ and $u_{l}=u\left(W_{l}\right)$, then the null programming becomes

$$
\begin{aligned}
& \left(P^{\prime}\right): \max _{u_{h}, u_{l}} \pi\left(H-w\left(u_{h}\right)\right)+(1-\pi)\left(L-w\left(u_{l}\right)\right) \\
& \text { s.t. }(I R) \pi u_{h}+(1-\pi) u_{l}-\varphi \geq 0 \\
& (I C) \pi\left(u_{h}-\varphi\right)+(1-\pi)\left(u_{l}-\varphi\right) \geq u_{l}
\end{aligned}
$$
that

The two constraints are constrictive and we can obtain

$$
u_{l}^{S B}=0, u_{h}^{S B}=\frac{\varphi}{\pi}
$$

As $w^{\prime}(\bullet)>0$, we have $W_{h}^{S B}=w\left(\frac{\varphi}{\pi}\right)>W_{h}^{*}=w(\varphi)$ and $W_{l}^{S B}=0<W_{l}^{*}=w(\varphi)$, indicating that college English teachers obtain higher wages under asymmetric information than under perfect information if the scientific output is high $(\mathrm{H})$ but lower wages if the scientific output is low (L). It is obvious that $W_{h}^{S B}>W_{h}^{*}>W_{l}^{S B}$, indicating that the management layer have to pay college English teachers risk premium $\left(\frac{(1-\pi) \varphi}{\pi}\right.$ measured by utility) and entail them part of risks, which is coordinated with the practice. In fact, the academic achievements of college teachers are encouraged and rewarded and are essential for their promotion of professional title. Otherwise, college teachers may lose their scientific laboratories, scientific sponsors or even their administrative positions, of course the wages will be reduced.

\section{Optimal Incentive Contract Under Repeated Moral Hazard}

If the career of one college English teacher can be divided into two periods, the incentive problem confronting the management layer is how to guide teachers to make greater effort in the scientific work in both periods of their career. There are two types of incentive contracts for the management layer to choose from, that is to repeatedly implement the incentive contract under one-period moral hazard mentioned in the above section or to carry out tenure incentive contract. We introduce faculty tenure into our model, dividing the career of teachers into two periods: pretenure period and tenure period. All college teachers have to work hard so as to obtain the qualification of teachers with tenure. The pre-tenure period is regarded as a probation period and teachers with excellent performance in scientific work are qualified as tenure teaching positions while those with poor scientific performance are to be fired. Rational management layer will inevitably choose the incentive contract with lower costs. We will then prove hereafter that compared with the optimal incentive contract under singleperiod moral hazard, the management layer under Tenure contracts confronts a trade-off between the benefits from income smoothing and the excess burden led by induced high level of effort in the second period. On the one hand, the Tenure contracts lead to the income smoothing of college English teachers and a reduction of incentive wages for scientific research in the first period of teachers' career(pretenure period). On the other hand, the management layer has to pay much more to stimulate college English teachers with tenure to work hard in scientific research.

According to the analyses above, we can describe the game between the management layer and college English teachers under tenure contracts as follows: at the beginning of the pre-tenure period, the management layer of colleges sign a long-run contract, determining the terminal wages and the conditions for a teaching position with tenure; at the end of the pre-tenure period, the management layer pays teachers $W_{1 h}$ and reward them a position with tenure if the observed scientific output of the teacher is $H$ while pays $W_{1 l}$ and fire the teacher provided the observed scientific output is $L$; at the end of the second period, if the observed scientific output is $H$, the teacher is paid $W_{2 h}$, otherwise $W_{2 l}$.

Therefore, the principal (the management layer) have to solve the following programming problem so as to induce the teachers to provide high level of effort in both periods under repeated moral hazard game: 


$$
\begin{aligned}
& (P): \max _{W_{1 h}, W_{1 l}, W_{2 h}, W_{2 l}} \pi\left(H-W_{1 h}\right)+(1-\pi)\left(L-W_{1 l}\right) \\
& +\pi^{2}\left(H-W_{2 h}\right)+\pi(1-\pi)\left(L-W_{2 l}\right) \\
& \text { s.t. }(I R) \pi u\left(W_{1 h}\right)+(1-\pi) u\left(W_{1 l}\right)-\varphi \\
& +\pi^{2}\left[u\left(W_{2 h}\right)-\varphi\right]+\pi(1-\pi)\left[u\left(W_{2 l}\right)-\varphi\right] \geq 0 \\
& (I C 1) \pi u\left(W_{1 h}\right)+(1-\pi) u\left(W_{1 l}\right)-\varphi+\pi^{2}\left[u\left(W_{2 h}\right)-\varphi\right] \\
& +\pi(1-\pi)\left[u\left(W_{2 l}\right)-\varphi\right] \geq u\left(W_{1 l}\right) \\
& (I C 2) \pi u\left(W_{2 h}\right)+(1-\pi) u\left(W_{2 l}\right)-\varphi \geq u\left(W_{2 l}\right)
\end{aligned}
$$

Where (IR) represents the participating constraint of college English teachers, (IC1) and (IC2) represent the incentive comparability constraint in the pre-tenure period and tenure period respectively.

$$
\text { Let } u_{1 h}=u\left(W_{1 h}\right), u_{1 l}=u\left(W_{1 l}\right) \quad u_{2 h}=u\left(W_{2 h}\right) \text {, }
$$

$u_{2 l}=u\left(W_{2 l}\right) \quad\left(u_{1 h}, u_{1 l}, u_{2 h}, u_{2 l} \geq 0\right)$, then the programming problem $P$ becomes $P^{\prime}$ :

$$
\begin{aligned}
& \left(P^{\prime}\right): \max _{u_{1 h}, u_{1 l}, u_{2 h}, u_{2 l}} \pi\left[H-w\left(u_{1 h}\right)\right]+(1-\pi)\left[L-w\left(u_{1 l}\right)\right] \\
& +\pi^{2}\left[H-w\left(u_{2 h}\right)\right]+\pi(1-\pi)\left[L-w\left(u_{2 l}\right)\right] \\
& \text { s.t. }(I R) \pi u_{1 h}+(1-\pi) u_{1 l}-\varphi+\pi^{2}\left[u_{2 h}-\varphi\right] \\
& +\pi(1-\pi)\left[u_{2 l}-\varphi\right] \geq 0 \\
& (I C 1) \pi u_{1 h}+(1-\pi) u_{1 l}-\varphi+\pi^{2}\left[u_{2 h}-\varphi\right] \\
& +\pi(1-\pi)\left[u_{2 l}-\varphi\right] \geq u_{1 l} \\
& (I C 2) \pi u_{2 h}+(1-\pi) u_{2 l}-\varphi \geq u_{2 l}
\end{aligned}
$$

It is easy to prove that (2), (3) and (4) are all constrict. The programming can be simplified as:

$u_{1 l}=0$

$u_{2 h}-u_{2 l}=\frac{\varphi}{\pi}$

$u_{1 h}+u_{1 l}=\frac{\varphi}{\pi}$

Then we can substitute (5), (6) and (7) into (1) and obtain the solution of the programming through derivation, where the superscript $D$ represents dynamic model. The solution $\left(u_{2 l}^{D}\right)$ satisfy the following equation:

$\left[w^{\prime}\left(u_{2 l}^{D}\right)-w^{\prime}\left(\frac{\varphi}{\pi}-u_{2 l}^{D}\right)\right]+\pi\left[w^{\prime}\left(\frac{\varphi}{\pi}+u_{2 l}^{D}\right)-w^{\prime}\left(u_{2 l}^{D}\right)\right]=0(8)$

\section{MODEL ANALYSES}

From the above analyses, we can draw the following three propositions from the model.

Proposition 1. Colleges and universities is proposed to reduce the incentive intensity of scientific research necessary for teachers to obtain positions with tenure under tenure system and the tenure system does smoothes the incomes of teachers.

Proof: Compared with the case of single-period moral hazard, the principal (the college management layer) reduces the incentive intensity on college English teachers to work hard in scientific research in the pre-tenure period under tenure system. In the single-period moral hazard model, the management layer have to pay college English teachers a incentive wage $W_{h}^{S B}=w\left(\frac{\varphi}{\pi}\right)$ while $W_{1 h}^{D}+W_{2 l}^{D}$ in the pretenure period under tenure contract so as to promote college English teachers work hard in scientific research. According to the nature of $w(\bullet)$, $W_{1 h}^{D}+W_{2 l}^{D}=w\left(u_{1 h}^{D}\right)+w\left(u_{2 l}^{D}\right)<w\left(u_{1 h}^{D}+u_{2 l}^{D}\right)=w\left(\frac{\varphi}{\pi}\right)=W_{h}^{S B}$, indicating that the tenure system stabilizes the incomes of college English teachers compared with the case of singleperiod moral hazard and realized incomesmoothing $\left(W_{1 h}^{D}<W_{h}^{S B}\right)$. This is mainly because that college English teachers attach more importance to the payments in the future and shift some of the risks in the pretenure period to the tenure period under tenure system. As for the management layer, the "income smoothing effect" reduces the wage costs by $W_{1 l}^{D}+W_{2 l}^{D}-W_{h}^{S B}$.

Proposition 2. Under tenure system, the incentive intensity must be strengthened so as to make college English teachers work hard in scientific research in the tenure period.

Proof: According to equation (6), $u_{2 h}^{D}=w\left(u_{2 l}+\frac{\varphi}{\pi}\right)>w\left(\frac{\varphi}{\pi}\right)=W_{h}^{S B}$, indicating that college English teachers must be paid a high incentive wage to work hard under repeated moral hazard, which is coordinated with our intuition. In our model, the qualification of teaching position with tenure is defined as a minimum wage guarantee on the reserved wage, and teachers with tenure will be paid $W_{2 l}^{D}$ even they do not work hard in the tenure period. Therefore, the principal (the management layer) has to pay a higher incentive wage $W_{2 h}^{D}$ to stimulate those with tenure positions to work hard in the tenure period.

According to Proposition 1 and Proposition 2, the management layer confronts a trade-off between the benefits from income smoothing and the excess burden led by inducing high level of endeavor in the second period (tenure period). In fact, we can compare the expected costs of the principal (the management layer) in the above two cases (single-period moral hazard \& repeated moral hazard). 
In the case of tenure contract, the expected payment by the college management layer is:

$$
\begin{aligned}
& \pi W_{1 h}^{D}+(1-\pi) W_{1 l}^{D}+\pi(1-\pi) W_{1 l}^{D}+\pi^{2} W_{2 h}^{D} \\
& +\pi(1-\pi) W_{h}^{S B}+(1-\pi)^{2} W_{l}^{S B} \\
& =\pi\left\{\left[w\left(\frac{\varphi}{\pi}-u_{2 l}^{D}\right)+w\left(u_{2 l}^{D}\right)\right]+\pi\left[w\left(\frac{\varphi}{\pi}+u_{2 l}^{D}\right)\right.\right. \\
& \left.\left.-w\left(u_{2 l}^{D}\right)\right]+(1-\pi) w\left(\frac{\varphi}{\pi}\right)\right\}
\end{aligned}
$$

If the principal follow the incentive contract under singleperiod moral hazard, then the wage cost paid by the principal is:

$$
2 \pi w\left(\frac{\varphi}{\pi}\right)
$$

The cost of implementing tenure contract is less than repeated single-period contract provided that $(9)<(10)$. Let $a=(9), b=(10)$, then

$$
\begin{aligned}
& \frac{a-b}{\pi}=\left[w\left(\frac{\varphi}{\pi}-u_{2 l}^{D}\right)+w\left(u_{2 l}^{D}\right)-w\left(\frac{\varphi}{\pi}\right)\right] \\
& +\pi\left[w\left(\frac{\varphi}{\pi}+u_{2 l}^{D}\right)-w\left(u_{2 l}^{D}\right)-w\left(\frac{\varphi}{\pi}\right)\right]
\end{aligned}
$$

As $w^{\prime}(\bullet)>0, w^{\prime \prime}(\bullet)>0$, we have

$$
\begin{aligned}
& w\left(\frac{\varphi}{\pi}-u_{2 l}^{D}\right)+w\left(u_{2 l}^{D}\right)<w\left(\frac{\varphi}{\pi}\right) \\
& w\left(\frac{\varphi}{\pi}+u_{2 l}^{D}\right)-w\left(u_{2 l}^{D}\right)>w\left(\frac{\varphi}{\pi}\right)
\end{aligned}
$$

Obviously, the sign of equation (11) cannot be determined, and it is uncertain which incentive scheme is more efficient in saving costs. Therefore, based on the above analyses, we can have:
Proposition 3. It is uncertain whether the tenure system is advantageous for saving costs. Conclusions and Suggestions

\section{CONCLUSION}

This paper analyzes the efficiency of tenure system on inducing college English teachers' effort in scientific research in the framework of principal-agent model with repeated moral hazard. The studies in this paper find that the tenure system is advantageous for income smoothing and is proposed to be applied in the incentive contract of college English teachers. Besides, our study also finds that it is very hard to stimulate college English teachers with tenure to work hard after obtaining the qualification of tenure and therefore the college management layer has to pay much more to promote them to work hard in academic research.

\section{ACKNOWLEDGMENT}

This paper is sponsored by Higher Education \& Teaching Reform Project of Chongqing (No. 1203026). Liu Jianhui is the corresponding author of this paper.

\section{REFERENCES}

[1] X. J. Zhang, Q. Zhang, F. W. Liao, "Research on college teachers' multi-duty principal problem between teaching with scientific study", Research in Teaching, 2009, 32(2): 32-35.

[2] L. J. Zhang, Y. T. Wu, X. M. Cao, "Research on the Incentive Mechanisms for College Teachers Based on the Multi-task Principalagent Theory", Mathematics in Practice and Theory, 2008, 38(22): 52-57.

[3] J. Y. Chen, D. M. Yao, X. Luo, "Principal-agent Model in the Contract Design of College Faculty", Journal of Central University of Finance and Economics, 2011, 10: 82-87.

[4] A. Siow, "Tenure and Other Unusual Personn Practices in Academia", Journal of Law, Econmics, and Organization, 1998,14(1): 153- 173.

[5] L. Carmichael, "Incentives in Academics: Why is There Tenure", Journal of Political Economy, 1988, 96: 453- 472.

[6] M. McPherson, G. Winston, "The Economics of Academic Tenure: A Relational Perspective", Journal of Economic Behavior and Organization, 1983, 4(2): 163- 184.

[7] C. Kahn, G. Huberman, "Two-Sided Uncertainty and 'Up-or-Out' Contracts", Journal of Labor Economics, 1988, (6): 423- 44.

[8] S. Freeman, "Wage Trends as Performance Displays Productive Potential: A Model and Application to Academic Early Retirement", Bell Journal of Economics, 1977 (8): 419- 443. 